Research Article

\title{
Study on the Freeze-Thaw Problems in the Winter Construction of the Lianghekou Earth-Core Rockfill Dam and the Countermeasures for Prevention
}

\author{
Qihao Yu $\mathbb{D}^{1},{ }^{1}$ Xiu-Ling Ren $\mathbb{D}^{1},{ }^{1,2}$ Pan Yue $\mathbb{D}^{\mathbb{D}},{ }^{3}$ Gui-Ke Zhang $\mathbb{D}^{\mathbb{D}},{ }^{3}$ Jun-Feng Wang $\mathbb{D}^{1}{ }^{1}$ \\ Yan-Hu Mu $\mathbb{D}^{1}{ }^{1}$ and En-Long Liu $\mathbb{D}^{1,4}$ \\ ${ }^{1}$ State Key Laboratory of Frozen Soil Engineering, Northwest Institute of Eco-Environment and Resources, \\ Chinese Academy of Sciences, Lanzhou 730000, Gansu, China \\ ${ }^{2}$ University of Chinese Academy of Sciences, Beijing 100049, China \\ ${ }^{3}$ Yalong River Hydropower Development Company, Ltd., Chengdu 610065, Sichuan, China \\ ${ }^{4}$ State Key Laboratory of Hydraulics and Mountain River Engineering, College of Water Resources and Hydropower, \\ Sichuan University, Chengdu 610065, Sichuan, China \\ Correspondence should be addressed to Qihao Yu; yuqh@lzb.ac.cn
}

Received 2 March 2021; Revised 12 April 2021; Accepted 30 June 2021; Published 14 July 2021

Academic Editor: Shengwen Tang

Copyright (c) 2021 Qihao Yu et al. This is an open access article distributed under the Creative Commons Attribution License, which permits unrestricted use, distribution, and reproduction in any medium, provided the original work is properly cited.

\begin{abstract}
Winter construction in seasonally frozen soil areas is inevitable. The variation of ambient temperature causes the freeze-thaw of the filling soils and its impact is significant, and whether the countermeasures can be effectively established and adopted is particularly important for the management and control of the construction quality of the project. This paper conducts systematic research based on the winter construction process of the dam core wall of the Lianghekou Hydropower Station, which is the third highest earth-core rockfill dam in the world under construction. The results show that for the construction site in the seasonally frozen soil area, there is a development process of the short-term frozen soils for the filling soils under the environment with low temperature in winter. The soil underwent a high-frequency freeze-thaw process wherein it was frozen at night and completely thawed during the day. During the freezing process, a large number of thin-layered segregated ice developed inside the soil to form a thin-layered or integral cryostructure, which will have an adverse effect on the engineering properties and the quality of the filling soils. And, the field tests demonstrate that the filling compaction degree of the frozen soils is difficult to meet the designed requirements. In order to effectively cope with the adverse effect of the freeze-thaw on the construction quality during the construction process, based on the analysis of the freeze-thaw characteristics of soils and its influence, and the energy exchange process of soils on-site, the principles and methods for establishing the freeze prevention system during the winter construction process are established, and a comprehensive monitoring system suitable for on-site is established in this paper. This research will provide an important reference for the scientific management and efficiency improvement of the winter construction process of the dams in cold regions.
\end{abstract}

\section{Introduction}

The freeze-thaw process and freezing duration of soils are closely related to air temperature in the frozen soil regions [1-3]. Studies have found that air temperature, ground temperature, and moisture content of soils are the main factors that affect the initial freeze-thaw time of the active layer [4] and the speed of the freeze-thaw process of soils [5]. In the process of engineering construction, the freeze-thaw process of soils and the frost heave and thawing sedimentation have seriously affected the stability and safe operation of the engineering structures $[6,7]$. The freezing process of soils is often accompanied by shrinkage and expansion, water absorption and dehydration, and compaction processes, leading to the complex stress conditions and shear failure of soils [8]. They have a significant impact on the microscopic structure of soils, will change the permeability, strength, and mechanical properties of soils [9-15], and will affect the filling quality, 
permeability, and stability of the project. In order to avoid the adverse impact of the freeze-thaw process of soils on the project, different measures have been taken for freeze-thaw prevent and control. For example, controlling the temperature during the pouring process, using different thermal insulation materials for heat storage, or active heating [16], or adopting thin paving and dry grinding (the thickness of the loose paving soils is about $60 \mathrm{~cm}$ ) for the freeze prevention and control [17]. For example, during the construction of the Xiaolangdi Dam and the Shuiniujia Hydropower Station Dam in the low-altitude regions, in order to cope with the adverse effects of the winter construction, the main measures were to control the temperature and moisture content of soils, fill soils by district, and quickly pave, quickly compact, and quickly monitor the soils $[18,19]$. At the same time, during different construction periods, sealing treatment was done by flat rolling surface calendaring and covering the thermal insulation materials, and two layers of gravelly soil were used as the thermal insulation layer during the period that the construction stopped [19].

However, there are few researches regarding the freezethaw of soils and the freeze prevention and control problem during the filling process of the high earth-core rockfill dams in the high-cold and high-altitude seasonally frozen soil areas. Therefore, with the development of water conservancy and hydropower resources and the vigorous development of the project in high-altitude areas in western China, it is important to study the variation of freeze-thaw and engineering characteristics of soils during the freezing period, and to develop effective freeze prevention and control measures. And, this research will provide the theoretical basis and technical support for solving the problem of engineering frozen soil, improving the construction efficiency of the project in winter, and ensuring the filling quality of the project.

\section{Engineering Background}

The Lianghekou Hydropower Station is located on the main stream of the Yalong River in Yajiang County, Ganzi Tibetan Autonomous Prefecture, Sichuan Province, China. It is the "Leading" reservoir in the middle and lower reaches of the Yalong River, and is a controlling reservoir power station project of the cascade power stations in the middle and lower reaches of the Yalong River. It belongs to the gravelly earthcore rockfill dam with a maximum height of $295 \mathrm{~m}$, and is the second highest earth-core rockfill dam under construction in China and the third highest in the world. This region belongs to a typical high-cold and high-altitude region with the development of flakes and islands permafrost and seasonally frozen soil, and the seasonally freeze-thaw effect is strong [20-22]. The average elevation of the dam site is close to $3000 \mathrm{~m}$, the winter of this region is from late November to the early March of the following year with short sunshine duration, and the climate is cold and dry. The annual average air temperature in the dam site is about $10.9^{\circ} \mathrm{C}$, and the extreme minimum air temperature can reach up to $-15.9^{\circ} \mathrm{C}$. Since the filling of the dam core wall in November 2016, there are short-term and high-frequency freeze-thaw cycles in winter. The soil basically freezes at night and thaws during most period of the daytime, which seriously affects the filling speed and quality of the soils in the dam core wall. The interior of the dam core wall is filled with gravelly soil, and the contact region on both sides between the gravelly soil and the concrete cover is contact clay (the horizontal width is $4 \mathrm{~m}$ ). Gravelly soil is a mixture of silty clay and gravel with a certain particle size in the ratio of $6: 4$, the mass moisture content is about $8.1 \%$, and the corresponding dry density is about $2.2 \mathrm{~g} / \mathrm{cm}^{3}$. The filling mass moisture content and dry density of contact clay are about $16.8 \%$ and $1.81 \mathrm{~g} / \mathrm{cm}^{3}$, respectively.

During the construction of the dam core wall in the winter of 2016-2018 (November to March of the following year), the meteorological conditions, the freeze-thaw process of gravelly soil and contact clay were monitored in detail onsite. At the same time, the relationship between the stacking process of soils and ground temperature of soils, the influence of each work flow and time nodes in the construction process on the freeze-thaw process of soils, and the freeze prevention and control measures and their effectiveness were investigated in detail.

\section{Changing Characteristics and Impacts of the Freeze-Thaw of Soils}

During the filling process of the dam in winter, the freezethaw mainly affects the construction links of the dam core wall. In the environment with negative temperature, the analysis of the variation of the freeze-thaw of soils is helpful to understand the freeze-thaw characteristics of soils, and the analysis of the cryostructure characteristics generated inside the soils is beneficial to understand the reason of the variation of the engineering properties of soils under the effects of freeze-thaw.

3.1. Observational System. In order to monitor the data of the meteorological conditions, the ground temperature of gravelly soil and contact clay in the dam core wall and other different sites in the dam, the observational systems of the meteorological and the ground temperature of soils have been established at different sites of the dam. In order to avoid mutual interference between the engineering construction and observational process, and at the same time to obtain continuous and true observational data on-site, the meteorological observational system adopted a mobile weather observational station, that is, the weather station can move in a certain range of the center region of the dam core wall according to the construction process and the construction conditions of machines on-site, and the weather station was always in working condition. The observational contents of the weather station included the conventional observational items such as wind speed and direction, air temperature, total solar radiation, and precipitation. The ground temperature observational system was mainly arranged in the region where the contact clay and gravelly soil were stopped filling, conducted alternately and continuously at intervals of multiple days. The schematic diagram of the ground temperature observational system of gravelly soil and contact clay with and without covering the 
thermal insulation materials on the surface of the dam core wall is shown in Figure 1. The ground temperature probe was a thermistor temperature sensor (the accuracy is $0.01^{\circ} \mathrm{C}$ ), and the interval of the observational depth from the ground surface to $12 \mathrm{~cm}$ was $3 \mathrm{~cm}$; the intervals from $12 \mathrm{~cm}$ to $100 \mathrm{~cm}$ were $8 \mathrm{~cm}, 14 \mathrm{~cm}, 26 \mathrm{~cm}$, and $40 \mathrm{~cm}$, respectively. The temperature data were collected by the CR3000 data logger (Campbell Scientific, Inc., U.S.), and the time interval was $10 \mathrm{~min}$.

3.2. Changing Process of Air Temperature in the Winter Construction Period. Figure 2 shows the changing process of air temperature with time in the dam core wall at an interval of 10 min from November 22, 2016, to February 28, 2017. In order to analyze the variation characteristics of air temperature within one day $(24 \mathrm{~h})$ in the winter observational period, the data of air temperature in the dam core wall from 20:00 on January 15 th to $20: 00$ on January 16 th, 2017, is selected for analysis. The daily changing process curve of air temperature on the coldest day of the winter is shown in Figure 3, and it typically represents the daily variation characteristics of air temperature in winter. It can be found from Figure 3 that air temperature is negative at night, reaching a certain value of negative temperature and continuing for a period, while the temperature is positive during the rest of the period. In addition, it can be seen from Figure 2 that air temperature is negative on most of the nights, so the soils will basically freeze on most of the nights.

Table 1 shows the statistical results of air temperature and the maximum frozen depth of the compacted gravelly soil without covering the thermal insulation materials in different periods. It can be seen from the table that from early December to early February of the following year, the frequency of the occurrence of negative air temperature at night, about $88 \%$, is the largest. Therefore, the freezing phenomenon of soils mainly occurs during this period. However, from late November to early December and midto-late February of the following year, both the frequency of the occurrence of negative air temperature and the freezing of soils are relatively low. At the same time, the statistics of the maximum frozen depth of the compacted gravelly soil that were observed on-site during the corresponding period with different daily minimum air temperatures is shown in Table 1. It can be seen from Table 1 that during the observational period, when the daily minimum air temperature is below $-5^{\circ} \mathrm{C}$, the maximum frozen depth of gravelly soil can reach up to about $19.7 \mathrm{~cm}$.

3.3. Variation of Freeze-Thaw and Its Effects on the Soils. As the variation of ambient temperature, the effects caused by the freeze-thaw of soils are mainly manifested in the formation of cryostructure inside the soils, and the variation of the engineering properties of the soils.

3.3.1. Formation of Cryostructure inside Soils and Its Influence. During the winter construction of the dam, under the effect of the negative air temperature, and during

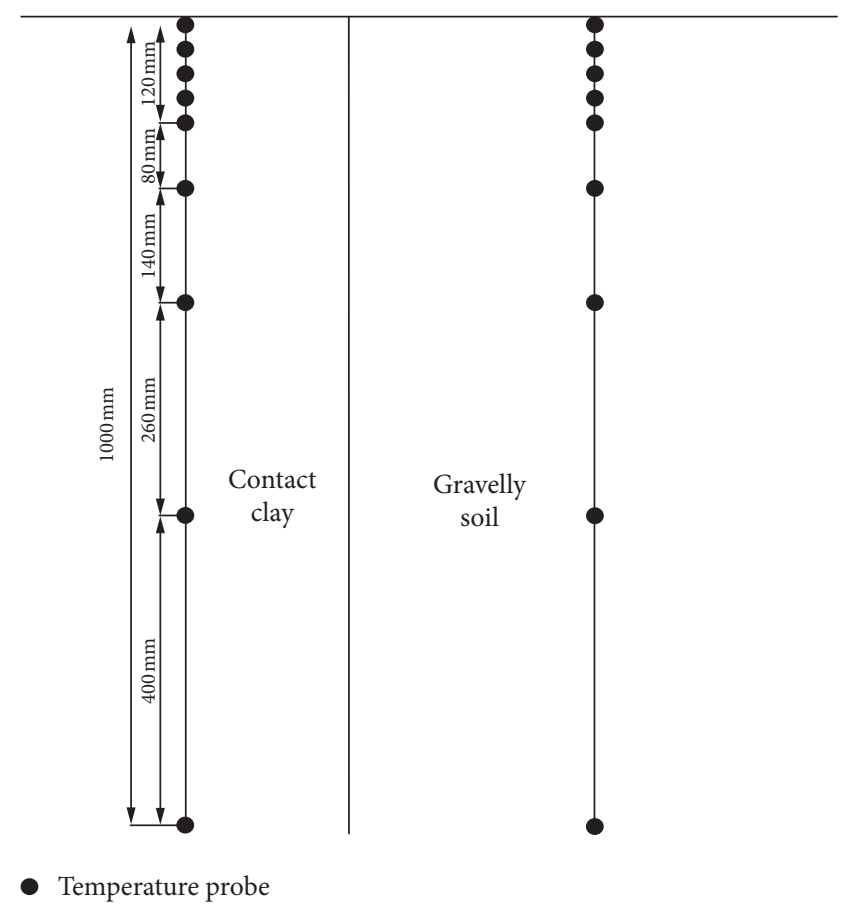

FIGURE 1: Schematic diagram of the ground temperature observational system.

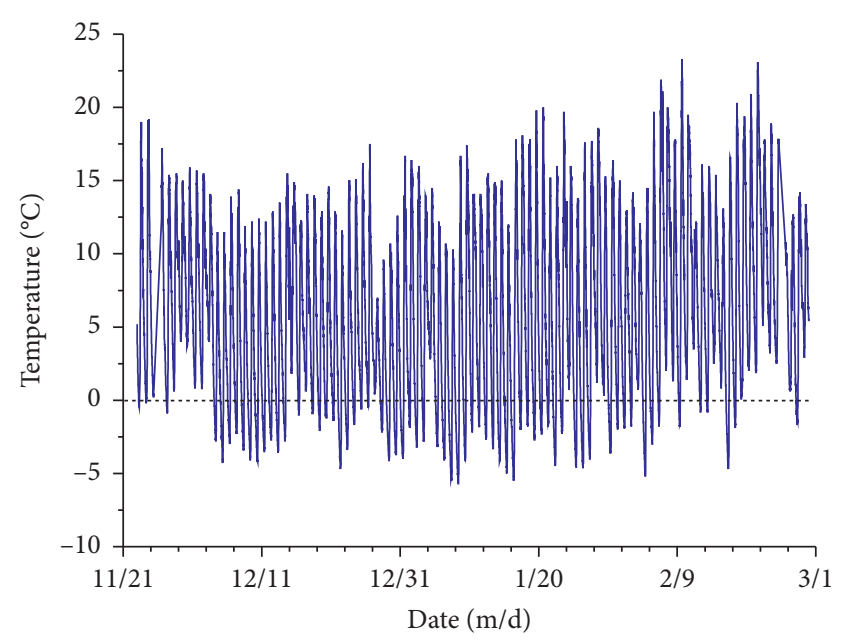

FIgURE 2: Variation of air temperature of the dam core wall from November 22, 2016, to February 28, 2017.

the freezing process of the filling soil from the ground surface downward, not only the ground surface was frozen but also the moisture inside the soil migrated to the freezing front, aggregated, and coagulated, resulting in the relative spatial arrangement of the solid components such as soil particles, segregated ice in the frozen soil, that is, cryostructure [23]. Under the on-site environmental conditions, the contact clay frozen at a depth of about $10-15 \mathrm{~cm}$, and mainly developed the thin segregated ice with the thickness of about $1 \mathrm{~mm}$, further formed a thin-layered cryostructure (Figure 4). Gravelly soil mainly formed the integral cryostructure with integral freezing and without obvious development of segregated ice inside, and it was 


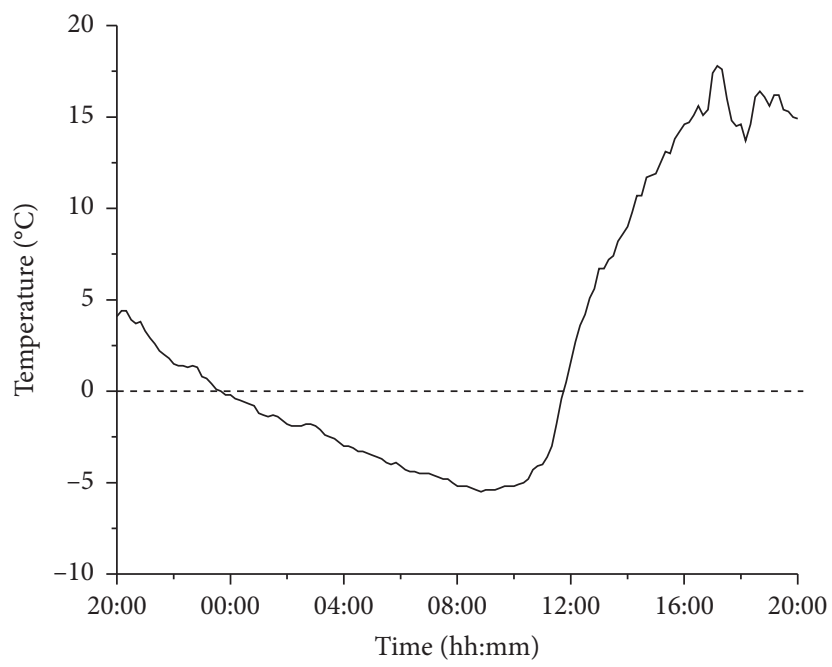

FIgURE 3: Variation of air temperature of the dam core wall with time from 20:00 on January 15th to 20:00 on January 16th, 2017.

TABLE 1: Statistical results of air temperature and the maximum frozen depth of the compacted gravelly soil without covering the thermal insulation materials.

\begin{tabular}{|c|c|c|c|c|c|c|}
\hline \multirow{3}{*}{ Stage } & \multirow{3}{*}{ Period } & \multicolumn{4}{|c|}{ The number of days (day) } & \multirow{3}{*}{$\begin{array}{l}\text { Frequency of the } \\
\text { occurrence of negative } \\
\text { air temperature (\%) }\end{array}$} \\
\hline & & \multirow{2}{*}{$\begin{array}{l}\text { Total number } \\
\text { of days (day) }\end{array}$} & \multicolumn{3}{|c|}{$\begin{array}{c}\text { Daily minimum air } \\
\text { temperature }\left({ }^{\circ} \mathrm{C}\right)\end{array}$} & \\
\hline & & & $0 \sim-3$ & $-3 \sim-5$ & $<-5$ & \\
\hline Stage 1 & $16 / 11 / 22-16 / 12 / 3$ & 12 & 3 & 0 & 0 & 25 \\
\hline Stage 2 & $16 / 12 / 4-17 / 2 / 6$ & 65 & 30 & 23 & 4 & 88 \\
\hline Stage 3 & $17 / 2 / 7-17 / 2 / 18$ & 19 & 4 & 1 & 0 & 26 \\
\hline \multicolumn{2}{|c|}{$\begin{array}{l}\text { The maximum frozen depth of } \\
\text { gravelly soil }(\mathrm{cm})\end{array}$} & & 14.2 & 16.0 & 19.7 & \\
\hline
\end{tabular}

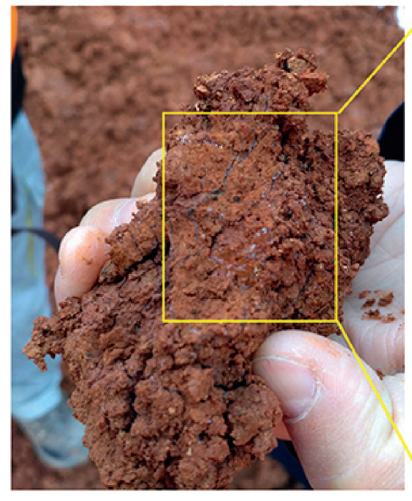

(a)

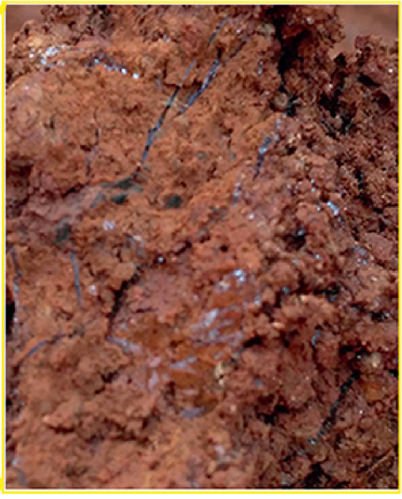

(b)

Figure 4: Photograph of the thin-layered cryostructure inside contact clay on-site.

more prominent in the compacted soils (Figure 5). As the ambient air temperature rises, the ice interlayer in the frozen soil will thaw and the moisture will dissipate. However, for the filled soils that have been compacted, firstly, for the soils affected by freeze-thaw, during the process of the moisture migration and the formation of ice interlayer, $9 \%$ volume expansion due to the water-ice phase transition will increase the volume of frozen soil, which will

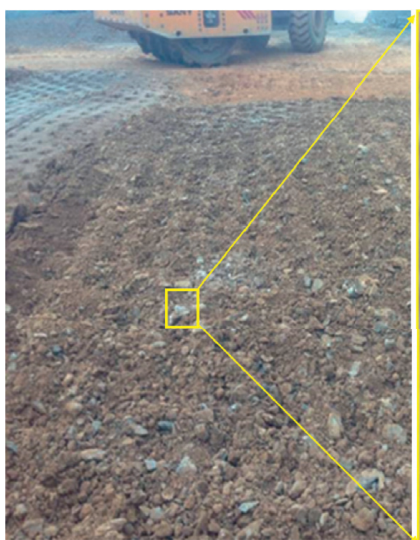

(a)

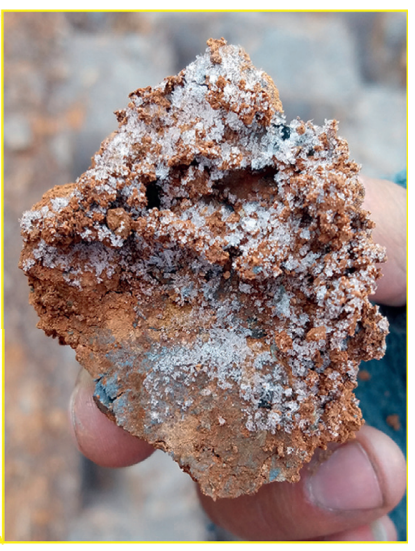

(b)
FIGURE 5: On-site rolling and compacting test of gravelly soil during the winter construction process (a) and the frozen soil block that is difficult to compact (b).

further lead to the decrease of the compaction degree of the compacted filling soils, thus deviating from the quality requirements of the project. Secondly, the horizontal permeability and the filling quality of the soils in the dam core wall will be affected by the unidirectional freeze-thaw cycle from the ground surface downward. 
3.3.2. Impacting of Freeze-Thaw on the Engineering Properties of Soils. The basic physical properties of soils will change after freeze-thaw [24-26], which will further change the engineering properties of soils [27-30]. Under the influence of freeze-thaw, the density of the compacted soil decreases, the void ratio of soil increases, and the permeability coefficient of soil increases by about 1 to 2 orders of magnitude [31-33]. The results of laboratory mechanical tests on different types of soils show that in an environment with low temperature, the strength of soils after being frozen is higher than that of soils before being frozen, and as the temperature continues to decrease, the compressive strength of soils continues to increase $[27,34,35]$. In order to further verify the influence of frozen soil on the compaction degree of the filling soil, the field rolling and compacting test of the frozen soil was carried out in the winter of 2016 (Figure 5). The convex block rolling and compacting machine (Hunan Sany Road Machinery Co., Ltd., China) was used to perform vibration rolling and compacting 10 times according to the normal process, and then the detection of the field compaction degree index was carried out. Firstly, it was found through detecting that after the frozen soil was rolled and compacted, although the larger frozen soil blocks on the surface were significantly reduced, there were still a large number of small frozen soil blocks, and there were still some frozen soil blocks with a diameter of about $10 \mathrm{~cm}$ at the bottom of the compacted layer. Secondly, the detecting data (Table 2) of the compaction degree of the gravelly soil after being rolled and compacted show that under the condition that both the moisture content and dry density of the soil remain basically unchanged, the compaction degree of the specimen is far less than or far away from the compaction degree requirement of $99 \%$, and the minimum compaction degree of one of the specimens is only $85.1 \%$. The field rolling and compacting test in winter proves that in this case, as the soil freezes and the compressive strength increases greatly, the compaction degree of the soil is difficult to meet the actual needs on-site.

\section{Basic Analysis of the Freeze Prevention and Control of Soils}

It can be seen from the above analysis that the freeze-thaw will have an important impact on the engineering properties and quality of the filling soils. Therefore, the effective organization of the winter construction process of the dam and the control of key links are particularly important for the improvement of field work efficiency. The analysis of the variation and mechanism of the freeze-thaw of soils can provide a theoretical basis for the establishment and selection of various subsequent prevention and control measures of freeze-thaw.

4.1. Freeze-Thaw Process of Soils On-Site. Figure 6 shows the changing process of the ground temperature of gravelly soil on-site from 20:00 on January 15th to 20:00 on January 16th, 2017. The vertical axis is from the ground surface to the observational depth, and the horizontal axis is the observational time. The contour in the figure is the ground temperature isotherm, the zone enveloped by $0^{\circ} \mathrm{C}$ isotherm is the changing range and process of the freezing of soil in the depth direction with time, and the rest are the unfrozen zone. As can be seen from the figure, the freezing process of gravelly soil is mainly manifested as unidirectional freezing process that starts from the ground surface and is continuously deepening, while the thawing process is manifested as a bidirectional thawing process that mainly thaws from the ground surface downward, and secondly thaws from the bottom of the frozen layer upward. In this paper, the daily freezing duration of gravelly soil refers to the time interval between the start and end freezing time of soil. The daily thawing duration refers to the time interval between the start thawing time and the total thawed time of soil. The freezing duration is relatively long and occupies most of the duration of the freeze-thaw process of soil, while the thawing duration is relatively short. At the same time, it is found through the statistical analysis of the data that the start thawing time for the frozen soil is generally about 9:00 to 10:00, and the latest thawing time is about 12:00. The duration varies according to the frozen depth of soil and the environmental conditions.

Figure 7 shows the variation of daily thawing duration of the compacted gravelly soil without covering the thermal insulation materials on the dam core wall from December 18, 2016, to February 22, 2017. The observational data show that the frozen soil could completely thaw after the ground surface begins to thaw for about $3 \mathrm{~h}$ in the morning of the coldest period in winter. Therefore, it can be seen from the spatial and temporal change characteristics of soils that during the thawing process, the thawing of the ground surface does not mean that the frozen soil has completely thawed. It should be combined with the observational data of the on-site ground temperature to control the start time of construction in the dam core wall during the daytime, so as to avoid a situation wherein the soil is difficult to compact due to the existence of the frozen soil blocks inside the soil after the construction starts, which will affect the filling quality of the project.

4.2. The Effect of Freeze-Thaw on Different Types of Soils. Although some studies have shown that the freeze-thaw will affect the engineering properties of soils and change the soil structure, the arrangement, and connection of soil particles [25], resulting in a significant weakening of the shear strength of soils $[36,37]$, the moisture content, low temperature, and action time are the main impacting factors [38]. In these studies, the freeze-thaw test conditions mostly with different low temperatures below $-5^{\circ} \mathrm{C}$, ten times to a dozen number of freeze-thaw cycles, and relatively high moisture content of soil. However, it is necessary to pay attention to the significant difference between the indoor test and the actual situation on-site, or how to correctly refer to the indoor research results in the engineering practice. Firstly, the moisture content of gravelly soil is only about $8.1 \%$, and the number of days when the daily minimum air temperature is below $-5^{\circ} \mathrm{C}$ is very limited at the Lianghekou construction site. Secondly, when the minimum ground 
TAвLE 2: Basic indicators after being field rolled and compacted of the filled gravelly soil.

\begin{tabular}{lcccccc}
\hline Number & $\begin{array}{c}\text { Air temperature } \\
\left({ }^{\circ} \mathrm{C}\right)\end{array}$ & $\begin{array}{c}\text { Measured moisture } \\
\text { content }(\%)\end{array}$ & $\begin{array}{c}\text { Optimum moisture } \\
\text { content }(\%)\end{array}$ & $\begin{array}{c}\text { Dry density } \\
\left(\mathrm{g} / \mathrm{cm}^{3}\right)\end{array}$ & $\begin{array}{c}\text { Dry density control value } \\
\left(\mathrm{g} / \mathrm{cm}^{3}\right)\end{array}$ & $\begin{array}{c}\text { Compaction } \\
\text { degree }(\%)\end{array}$ \\
\hline 5 Yc2-1 & -1.3 & 10.6 & 9.0 & 1.99 & 2.083 & 94.0 \\
5 Yc2-2 & -2.2 & 10.5 & 9.1 & 1.95 & 2.105 \\
5 Yc2-3 & -4.9 & 9.5 & 9.1 & 2.04 & 2.095 & 92.3 \\
\hline
\end{tabular}

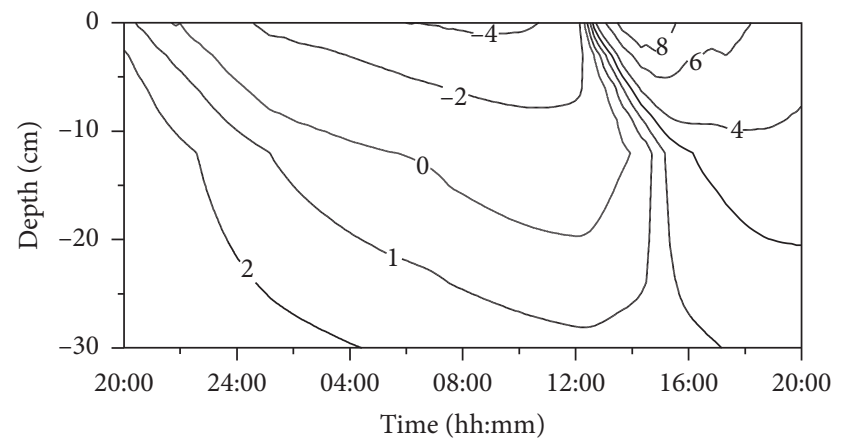

FIGURE 6: Changing process of ground temperature of the compacted gravelly soil without covering the thermal insulation materials on the dam core wall from 20:00 on January 15th to 20:00 on January 16th, 2017 (unit: ${ }^{\circ} \mathrm{C}$ ).

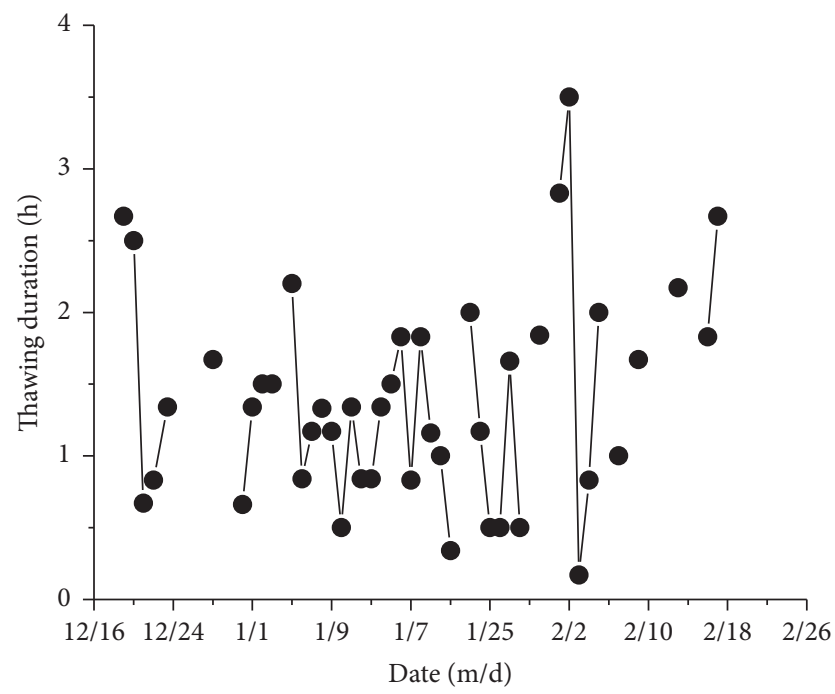

FIGURE 7: Variation of the daily thawing duration of the compacted gravelly soil without covering the thermal insulation materials on the dam core wall from December 18, 2016, to February 22, 2017 with time.

temperature is reached, the freezing duration of soil is relatively short. It can be seen from Figure 6 that during the $14 \mathrm{~h}$ freezing period of soil, the duration of the ground surface temperature that reaching the lowest temperature of $-4.5^{\circ} \mathrm{C}$ is only about $2 \mathrm{~h}$. And in most of the period, the ground temperature is about $-2^{\circ} \mathrm{C}$. Thirdly, the thickness of the frozen soil layer that reaches the low temperature is relatively thin. The depth of the surface soil with the ground temperature below $-4^{\circ} \mathrm{C}$ is only about $2 \mathrm{~cm}$ (Figure 6), which accounts for about $10 \%$ of the frozen depth of $19.7 \mathrm{~cm}$. In order to further verify the influence of the freeze-thaw process on the engineering properties of soils, relevant onsite and indoor tests were carried out during the construction process of the Lianghekou Hydropower Station in the winter of 2017, and the test results were consistent. Figure 8 shows the stress-strain relationship curves of gravelly soil with the initial moisture content of $9.0 \%$ after different numbers of freeze-thaw cycles at the cooling temperature of $-5^{\circ} \mathrm{C}$ and then compacted indoor. It can be seen from the figure that after gravelly soil underwent different numbers of freeze-thaw cycles and then compacted, when the number of freeze-thaw cycles is less than 5 , the variation of the strain of the soil specimens is small under the same stress condition. It indicates that under the condition that the minimum air temperature is higher than $-5^{\circ} \mathrm{C}$ and the number of freeze-thaw cycles is less than 5, the mechanical properties, permeability, and other engineering properties of gravelly soil after freeze-thaw cycles and then compacted will not affect the quality of the project. Due to space limitations, the permeability of gravelly soil is not analyzed here. Secondly, for the loose gravelly soil, due to the relatively large space between soil particles and small moisture content, the amount of moisture migration in the soil is small and the development of cryostructures is relatively limited after freezing. After the soil completely thawed, the limited residual cryostructure can be completely eliminated through the mutual dislocation and the rearrangement of soil particles during the rolling and compacting process of large machines. Therefore, during the period that the construction stops at night, it is a feasible and efficient way to cover the loose soils on the compacted soils, which is conductive to the rapid construction on-site. Reducing according to the conventional safety coefficient of the project, which indicates that as long as the frozen depth of soils does not exceed $60 \%$ of the thickness of the loose soil layer under the limited numbers of freeze-thaw cycles onsite, the method of covering the loose soil can be adopted.

However, for the compacted gravelly soil and contact clay, attention should be paid to the occurrence of the freezing of soils. Firstly, after the gravelly soil is compacted by the machine, the porosity of soil reduces greatly and the connection between the fine particles becomes closer (Figure 9), which results in good connectivity between the capillary water in the pores and the bound water in the outer layer of the particles. Under freezing conditions at night, large amount of unfrozen moisture migrates to the frozen front and it is easy to form an integral horizontal layered segregated ice, causing separation between soil layers, and its residual structure is easy to change the integral permeability. Therefore, the compacted gravelly soil should avoid the occurrence of the freezing phenomenon. Secondly, for contact clay, due to the large filling moisture content of 


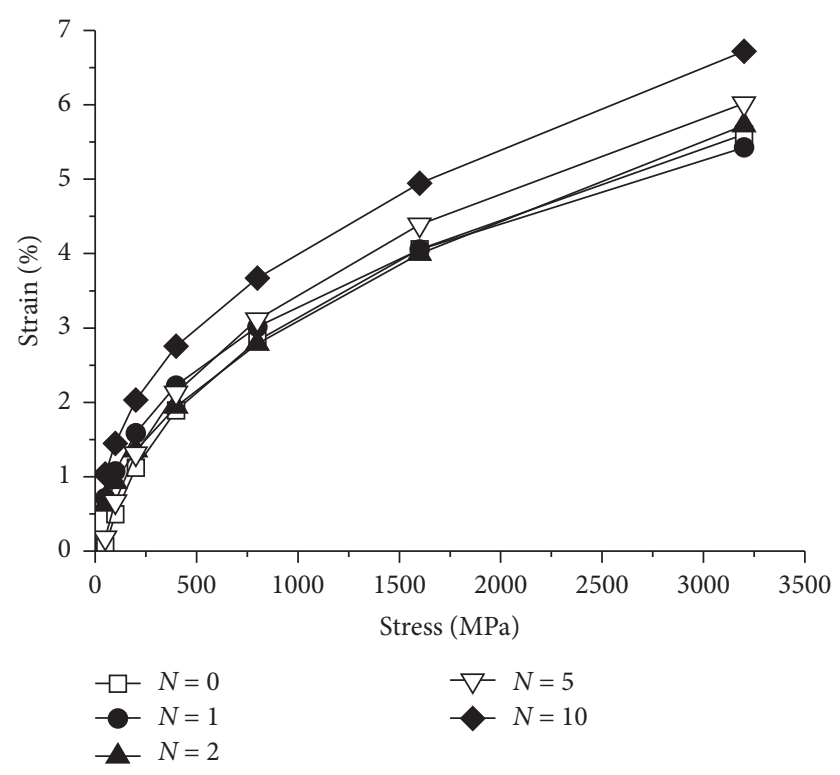

FIGURE 8: Stress-strain relationship curves of gravelly soil with a moisture content of $9.0 \%$ experiencing different numbers of freeze-thaw cycles at the cooling temperature of $-5^{\circ} \mathrm{C}$ and then being compacted.

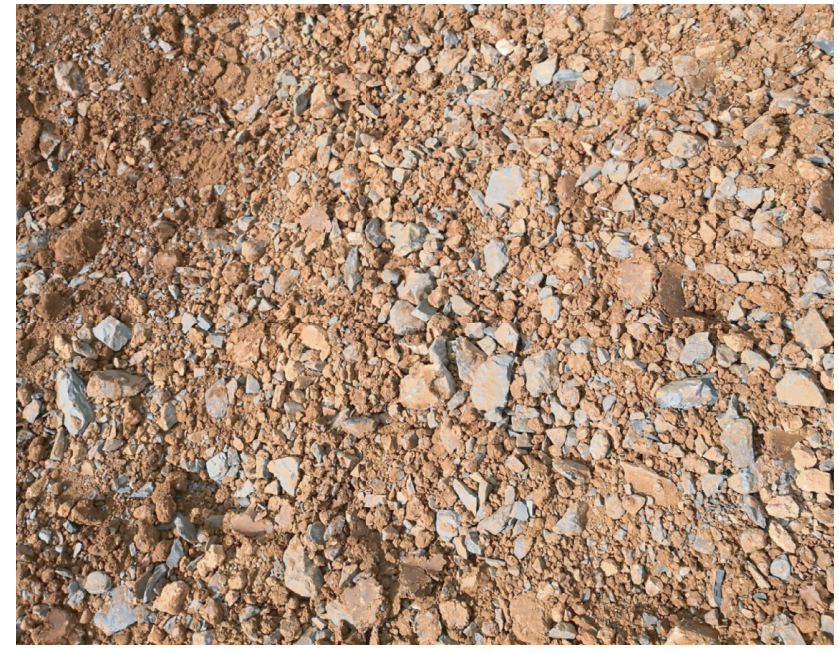

(a)

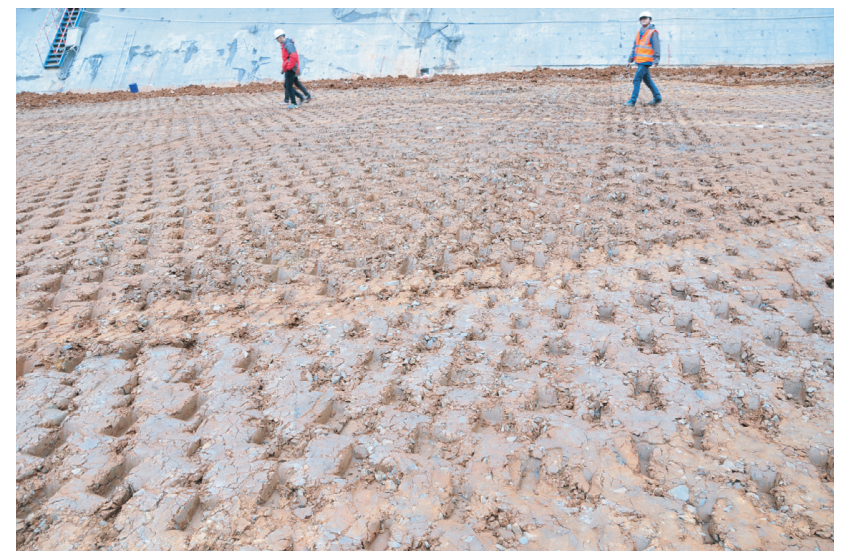

(b)

Figure 9: Photograph of gravelly soil before and after being compacted. (a) Loose gravelly soil. (b) Compacted gravelly soil.

about $17 \%$, it is easy to form a layered cryostructure under on-site freezing conditions (Figure 4), and considering the small proportion of contact clay on-site, the occurrence of the freezing phenomenon of the filled contact clay should also be avoided.

\subsection{Utilization and Control of the Energy Exchange Process of} Soils. Frozen soil has temperature below $0^{\circ} \mathrm{C}$ and contains ice, which is the result of heat exchange between the soil and the external environment. The formation of the frozen soil is firstly due to the continuous loss of heat energy inside the soil and the continuous drop in temperature. Secondly, when the water-ice phase transition process of soil around $0^{\circ} \mathrm{C}$ is completed and accompanied with the release of the large amounts of heat (the latent heat of water phase change is $335 \mathrm{~kJ} / \mathrm{kg}$ ), as well as the free water in the soil is compeletly frozen, the soil changes from the thawing state to the frozen state $[7,39,40]$. Thus, the circulation continuously drives the freezing of the underlying soil and the deepening of the frozen depth (Figure 6). At the same time, the heat capacity of the filling soil affected by factors such as temperature, compaction degree, and moisture content are the basic conditions for the inherent variation of soil, while the interface state between the ground surface and atmosphere (roughness of the soil surface, whether there is soil blocker, etc.) is the important external factor that affects the strength of their interaction. Among them, the inherent and external factors can be manually intervened and controlled during the winter construction process. For example, it is possible to 
increase the temperature of the incoming soil, or maintain and slow down the cooling process of the compacted soil. The surface layer is covered with thermal insulation materials, for actively controlling the temperature of the surface layer and preventing the soils from freezing through the energy supplement methods. And, by increasing the moisture content of the surface layer, extending the duration to complete the water-ice phase transition process around $0^{\circ} \mathrm{C}$ is a feasible theoretical basis for freeze prevention and control.

\section{Establishment of the Freeze Prevention and Control System of Soils}

The establishment of the freeze prevention and control system mainly includes the principles, methods, and implementation approaches of prevention and control, as well as the monitoring systems, and which should be able to play an effective role in the actual projects.

\subsection{Establishment of the Prevention and Control Principles.} The establishment of the prevention and control principle of dam construction in winter is the foundation of various prevention and control works, and it will also have an important impact on the construction efficiency and filling quality. Through the continuous analysis and summary of the prevention and control principles during the three winter constructions of the Lianghekou Hydropower Station, a set of principles and technical systems suitable for the winter construction of dams in the seasonally frozen soil areas in China have been explored and established.

In 2016, for the first time in the winter construction process of the dam core wall of the Lianghekou Hydropower Station, the requirements of "cannot freeze" for the filling soils per the specification was followed [41]. And, the construction principle of "the frozen soil cannot fill the dam and the filled soil in the dam cannot freeze" was established, that is, the soil mixed in the Canpeichang and the soil pulled by the construction vehicles must not contain the frozen soil, and all the filled soil in the dam core wall must not be frozen. Based on this principle, under the environment with low temperature, the soil mixed in the Canpeichang, during the transportation process by vehicles and in the dam core wall were all covered with the thermal insulation materials. And in order to ensure that the filled soil will not freeze, adjusted covering single-layer or double-layer thermal insulation materials at anytime according to the monitoring situation on-site. Under these kinds of construction conditions, for the construction area of nearly $20,000 \mathrm{~m}^{2}$ of the dam surface, it took a lot of time for manual covering and putting away the thermal insulation materials, and the time taken for covering and putting away the thermal insulation materials was about $2 \mathrm{~h}$ and $3 \mathrm{~h}$ each day, respectively. The dam core wall was rectangular along the river in the initial stage of filling the dam core wall. In order to save the time for covering and putting away the thermal insulation materials, the dam surface was divided into two halves (upstream and downstream) along the direction perpendicular to the river according to the on-site construction requirements, and which carries out the construction alternately for a period of several days as a cycle. However, in this case, the effective construction duration was only about 9 to $10 \mathrm{~h}$ every day, which caused the construction progress in the winter of that year to fail to meet the requirements of the overall construction progress. More importantly, due to the impact of the energy exchange process of the filling soil, for the compacted soil the surface has been covered with the thermal insulation materials. And, as the soil has been in the process of releasing heat and the temperature of the soil has continued to decrease, the soil surface still was frozen under the environment with relatively high air temperature in midFebruary, 2017.

In view of the problems that occurred during the construction process in the winter of 2016 and 2017, through the successful research on the large-scale equipment for covering and putting away the thermal insulation materials and the significant improvement of efficiency, as well as the understanding of the energy balance process of soils, the principle of "fast construction" was further added based on the above construction principles. And, by adopting the construction measures of "the left and right banks were covered with the thermal insulation materials by circulation every day, and the upstream and downstream were subdivided into flow operations," that is, the dam core wall was divided into two halves of zones near the left and right banks, and the filling was carried out in rotation and with the small filling surface flow operation every day. The operation effectively avoided the long-term placement of the compacted soils and reduced the heat loss of the soils. The on-site ground temperature observational data show that since the initial temperature of the soils is basically maintained at $6-8^{\circ} \mathrm{C}$, the heat energy of the soils has been supplemented in time during the circulation construction process every day. Although the freezing index of air temperature of $-1069^{\circ} \mathrm{C} \cdot \mathrm{h}$ in the winter of 2017 is greater than that of $-969^{\circ} \mathrm{C} \cdot \mathrm{h}$ in 2016 , and the daily minimum air temperature of $-6.8^{\circ} \mathrm{C}$ in 2017 is $1.1^{\circ} \mathrm{C}$ lower than that of $-5.7^{\circ} \mathrm{C}$ in the previous year, that is, in the case of the relatively colder environmental conditions, the frozen depth of gravelly soil becomes shallower without covering the thermal insulation materials. Among them, by comparing the observational data during the same coldest period (January 9 to 14 of the following year), it can be seen that during the same period, under the premise that the negative accumulated air temperature of 2017 is greater than that of the previous year, the frozen depth of gravelly soil during the filling process in 2017 is reduced by about $50 \%$ on average compared with that of the previous year (Figure 10).

Based on the abovementioned field and indoor tests and the summary of experience, during the construction process in the winter of 2018, further perfected and established were the new construction principles, "the frozen soil cannot fill the dam, the frozen soil cannot be rolled and compacted, the soil after rolled and compacted cannot freeze, rapid construction, timely coverage." Among them, "the frozen soil cannot be rolled and compacted" means that the loose soil can undergo a limited number of freeze-thaw processes, but the frozen loose soil must be completely thawed before 


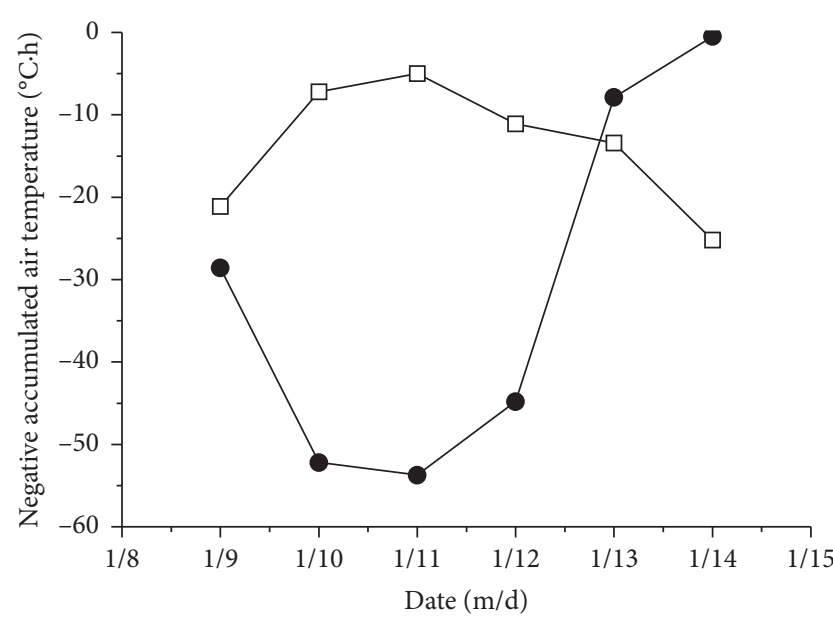

$\neg \square-2016$

- 2017

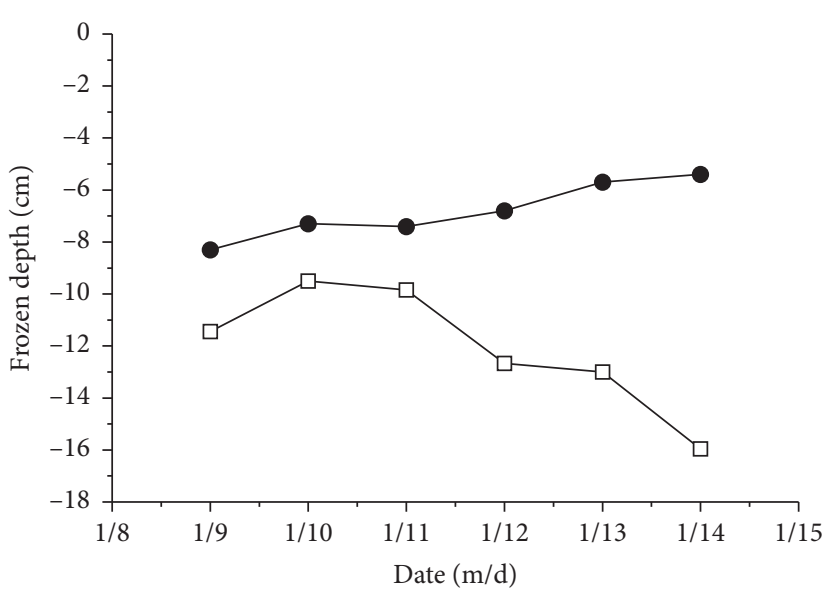

$-\square-2016$

- 2017

(a)

(b)

FIGURE 10: Variation of the negative accumulated air temperature and the frozen depth of the compacted gravelly soil without covering the thermal insulation materials with time from January 9 to 14, 2017 and from January 9 to 14, 2018. (a) Variation of the negative accumulated air temperature. (b) Frozen depth of the compacted gravelly soil without covering the thermal insulation materials.

subsequent rolling and compacting operations can be carried out. Based on the established ground temperature observational system (Figure 1), it can be determined that the internal of the loose soil is completely thawed when the internal temperature of the soil is all higher than $0^{\circ} \mathrm{C}$. "The soil cannot freeze after rolled and compacted" means that the filled soil after being rolled and compacted must ensure that it will not freeze to avoid the residual and adverse effects of cryostructures. "Rapid construction" means that the soils with relatively high temperature can enter the site in time, supply the heat energy in time, and enhance the capability of frost resistance. "Timely coverage" refers to the effective combination of specific measures such as timely coverage of loose soil and the thermal insulation materials to enhance the flexibility and initiative of the on-site construction process and improve the construction efficiency. The total filling volume of gravelly soil in the dam core wall during the winter construction period is shown in Table 3. As the construction period in winter is not exactly the same every year, the data are calculated from the end of November of the current year to the middle of February of the following year for the unified comparison. It can be seen from the table that with the continuous improvement of the annual construction principles, the filling volume of gravelly soil continues to increase. Through the establishment of the construction principles, the construction quality is effectively ensured and the goal of preventing floods from flooding is successfully realized, which lay a solid foundation for the power station to shut down the gates and store water on schedule.

5.2. Selection of the Methods for Prevention and Control of the Freeze-Thaw of Soils. Based on the establishment of the above prevention and control theoretical basis and construction principles, a relatively effective prevention and
TABLE 3: Total filling volume of gravelly soil of the dam core wall during the winter construction.

\begin{tabular}{lccc}
\hline Year & 2016 & 2017 & 2018 \\
\hline $\begin{array}{l}\text { Total filling volume of gravelly soil } \\
\left(\text { million } \mathrm{m}^{3}\right)\end{array}$ & 9.9 & 20.5 & 24.3 \\
\hline
\end{tabular}

control system can be formed by adopting the feasible methods to ensure the efficient and smooth construction of the dam core wall in winter.

5.2.1. The Measure of Covering the Thermal Insulation Materials. The thermal insulation measures are mainly to reduce the heat dissipation of soil and reduce the temperature by covering the ground surface with the thermal insulation materials and changing the heat exchange conditions on the surface of soil. Figure 10 shows the changing process of the ground surface temperature of the compacted gravelly soil with and without covering the thermal insulation materials on the dam core wall in the winter of 2016. It can be seen from the observational data that the ground surface temperature of gravelly soil is basically negative every day without covering the thermal insulation materials, while it is basically positive with covering the thermal insulation materials, and the negative temperature only occurs on three days, indicating that the soil has basically not frozen. It can be seen that using the thermal insulation materials to cover the surface of the dam core wall can greatly reduce or eliminate the freezing of soils. Although it is difficult to cover and put away the thermal insulation materials on the dam core wall with an area of $10,000 \mathrm{~m}^{2}$ of the filling surface, the invention and application of the retractable machines has improved the construction efficiency and made this construction method feasible. And, covering 
the thermal insulation materials should be one of the important freeze prevention and control measures during the winter construction process.

As this kind of measure will increase the construction cost and have a certain impact on the construction schedule, attention should be paid to the following problems during the implementation process. The first problem is the selection of the types of the thermal insulation materials. It is affected by the environment with low temperature at night. After the thermal insulation material is covered, a large amount of condensed water will collect on the surface of the thermal insulation material that is in contact with the soil, which will have a greater adverse effect on the thermal insulation, the difficulty of retracting, and the durability of the thermal insulation materials. Therefore, the materials should preferably have a waterproof film on the surface. Secondly, determination of the thermal insulation properties of the thermal insulation materials. The determination of the type and thickness of the intermediate fabric of the thermal insulation material is mainly based on different air temperature conditions on-site and the ground temperature conditions, and the thermal insulation performance of the geotextile is selected through the thermal calculations. Thirdly, considering that the thermal insulation material is retracted by large machines and the tensile strength of the materials can meet the requirements. With regard to the above aspects, through the full comparison, demonstration, and use of various thermal insulation materials of cotton, geotextiles, and different fabric structures in the Lianghekou Project, the preferred thermal insulation material is the special geotextile with the waterproof film on the top and bottom, and polypropylene with the mass of $500 \sim 800 \mathrm{~g} / \mathrm{m}^{2}$ in the middle. Fourthly, in the implementation process of this kind of measure, through the determination of the implementation time and target of this kind of measure, the comprehensive realization of the best economic and engineering effectiveness can be achieved. Combining the experiments in the Lianghekou region, it can be found from Figures 2 and 11 that in late December, or from the end of the current year to the beginning of February of the following year, air temperature is relatively low at night and the negative temperature basically exists. The compacted gravelly soil has a higher probability of freezing and the frozen depth is deeper without covering the thermal insulation materials, so the thermal insulation material should be covered. However, from mid-November to mid-December, and in February of the following year, both the frequency of the occurrence of negative air temperature at night and the freezing of the compacted gravelly soil without covering the thermal insulation materials are relatively low, or only the ground surface freezes and frosts. Therefore, not covering the thermal insulation materials on the gravelly soil in the dam core wall during this period is an option.

In addition, due to the relatively small proportion of contact clay, and the effect of freeze-thaw on the internal structure and engineering properties of soils, the dam of Lianghekou Hydropower Station has adopted complete and double protection measures, that is, when one layer of the thermal insulation material is used to cover gravelly soil, two

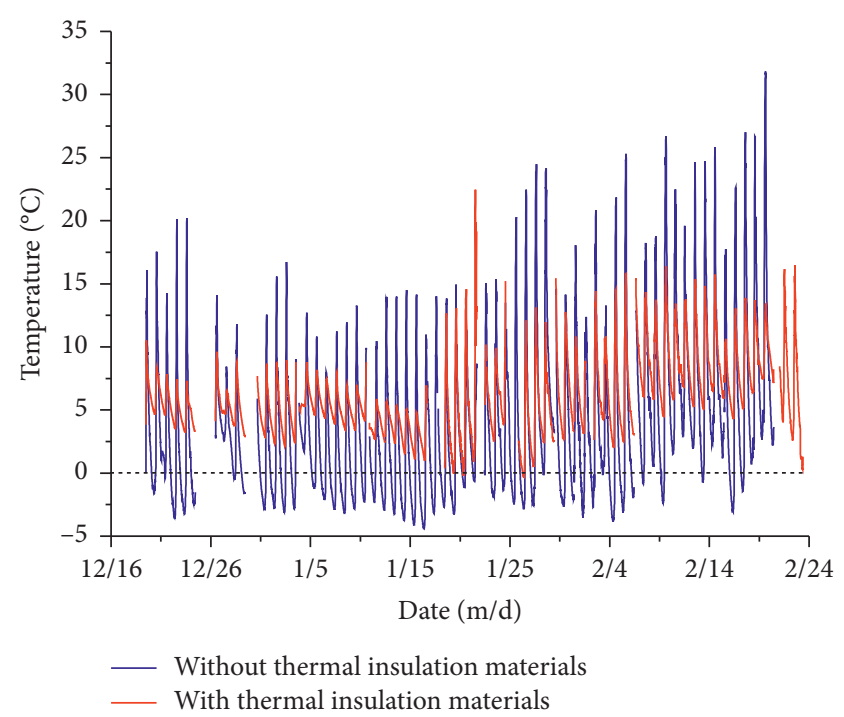

FIgURE 11: Variation of the ground surface temperature of the compacted gravelly soil with and without covering the thermal insulation materials on the dam core wall with time from December 18, 2016 to February 22, 2017.

layers of the thermal insulation materials are used to cover contact clay. Through the observations during the construction process in winter, it was found that contact clay did not freeze with covering the thermal insulation materials.

5.2.2. Covering Loose Soils. According to the above field and indoor test results for the engineering properties of soils under the conditions of covering loose soils, it has been found that the engineering properties of the loose soils remain unchanged when the minimum air temperature onsite is not below $-5^{\circ} \mathrm{C}$ and there a limited number of freezethaw cycles, and the engineering properties of soils still meet the construction requirements. Therefore, covering the loose soil on the compacted soil protects the lower soil layer from freezing and meets the normal construction process at the same time. Loose soil is relatively loose, the internal porosity is relatively large, and the overall thermal conductivity of soil is relatively small, which is beneficial to protect the lower compacted soil. Therefore, in the dam core wall of the Lianghekou Hydropower Station from the winter of 2017, the last process before the construction stopped was to cover the loose soil with a thickness of $30 \mathrm{~cm}$ on the compacted soil in the dam core wall. At the same time, this layer of soil entered the site toward the end before the construction stopped; the initial temperature of the soil was relatively high, which was beneficial for the further improvement of the frost resistance of soil. Subsequently, after a thorough inspection and confirming that the frozen soil had completely thawed on the following day, the follow-up rolling and compacting operations were carried out in time. Therefore, one of the important methods to improve the efficiency of engineering construction was to make reasonable arrangement and management of the on-site engineering procedures, rational use of the environmental conditions, and timely covering of the loose soils. 
5.2.3. Process Control in Different Seasons. It can be seen from Figure 2 that the changing process of air temperature of the construction site in winter shows that air temperature in the whole winter is at a negative state at night for most of the period. However, due to the difference in its magnitude characteristics and changing process, the thermal characteristics of the filling soil will cause the freeze-thaw characteristics (frozen depth, internal structure, etc.) of soils to change. Therefore, dividing different stages according to the changing process of environmental air temperature is conductive to the scientific control of the on-site construction links and the improvement of production efficiency.

Firstly, it can be seen from the abovementioned changing process and value characteristics of air temperature that, during the period of about 4 months in winter, the daily minimum air temperature is relatively high from mid-November to the end of the current year and February of the following year, the daily minimum air temperature in January of the following year is relatively the lowest, and the probability of freezing and the frozen depth of soils also change accordingly. Therefore, using the end of December of the current year and the beginning of February of the following year as the time nodes to divide the three phases of the winter construction period, and adopting different construction techniques in different periods will achieve better construction efficiency and economic benefits. In addition, statistics on the meteorological data of the dam core wall of the Lianghekou Hydropower Station in the winter of 2016-2018 found that the division nodes of the three periods will change in different years; these two time nodes have the characteristics of dynamically moving with the change of regional climate, that is, with the changing process of the long-term air temperature of 10-15 days in this region, the two time nodes will move forward or backward to different degrees. This phenomenon is very conductive to the control and decision-making of the on-site construction process.

Secondly, because the environment and the internal conditions of soils are different in different stages, different measures should be adopted in the construction process of the project. In the first stage, both the minimum air temperature and ground temperature at night are relatively high, and the soil has high heat storage and anti-freezing ability, which should not be frozen. It can adopt the construction methods of mainly covering the loose soil, and at the same time covering the thermal insulation materials under the extreme air temperature conditions. In the second stage, since the environment is the coldest in the entire winter, in order to weaken the freezing effect of loose soil and completely avoid the freezing of the compacted soil, the thermal insulation materials can be covered in time after paving the loose soils. In the third stage, although the ambient temperature is basically similar to that of the first stage, after the soil has undergone the heat release process in winter, the ground temperature of the lower filled soil is the lowest in the whole winter, and it is easier to cause the soil to freeze by the cooling of the external environment. For example, in mid-February, 2017, the air temperature at the Lianghekou
Hydropower Station rose significantly, but the ground surface was only partially frozen at night, which was then eradicated. Therefore, in this stage, it can comprehensively adopt the freeze prevention and control measures of the above two stages based on the on-site observational results.

5.2.4. Process Control of Time. This aspect is mainly the management and control of different time nodes in the construction process during the daily changing process. In terms of the construction process, based on the abovementioned analysis of the freeze-thaw characteristics of the filling soil, the rapid construction of the filling process of the dam surface can be timely covered by the filling soil during the daily circulation process. It can supply the thermal energy of the filling soil in time and slow down the cooling of the ground temperature of the lower soils, and maintain the ground temperature always at a high state, thereby improving the anti-freezing ability of the filling soils. The control of the process nodes mainly lies in the control of the stop time of the construction at night and the start time of construction the next day, and it is relatively difficult to control the stop time of the construction at night. Due to the later, the stop time of the construction at night, the lower the ground temperature, the heat release intensity of the soil will be stronger and the decreasing amplitude of the thermal energy accumulated in the soil will be larger, which will lead to a significant increase in the freezing probability of the soil. Therefore, the end time of construction at night, the completion paving time of the loose soil, or the late or early completion time of covering the thermal insulation materials will have completely different prevention and control effects. Figure 12 shows the variation of ground surface temperature of the loose gravelly soil with covering the thermal insulation materials at different times at night under different air temperature conditions on December 9 and 14, 2018. The observational data show that due to the different times of covering the thermal insulation materials, the covering times in Figures 12(a) and 12(b) are 0:20 and 23:10, respectively, and the difference between the time of covering the thermal insulation materials before and after is about $1.2 \mathrm{~h}$. Under the colder environmental conditions, the daily minimum air temperature is higher than that of the day with higher air temperature, and the duration of negative temperature is longer (Figure 12(b)). However, due to the timely coverage of the thermal insulation materials and the timely protection of the thermal energy, the ground surface temperature of soils always keeps at a positive temperature, and the soil does not freeze at night (Figure 12(b)). Under the environment with low temperature, the soil with covering the thermal insulation materials still freezes due to the long-time heat dissipation of soils (Figure 12(a)).

\subsection{Establishment of the Monitoring System for the Freeze-} Thaw State of Soils. In the winter construction process, the establishment of the on-site comprehensive monitoring system is the prerequisite and guarantee for the scientific management and control of the construction process and the assurance of project quality. Based on the analysis of the 


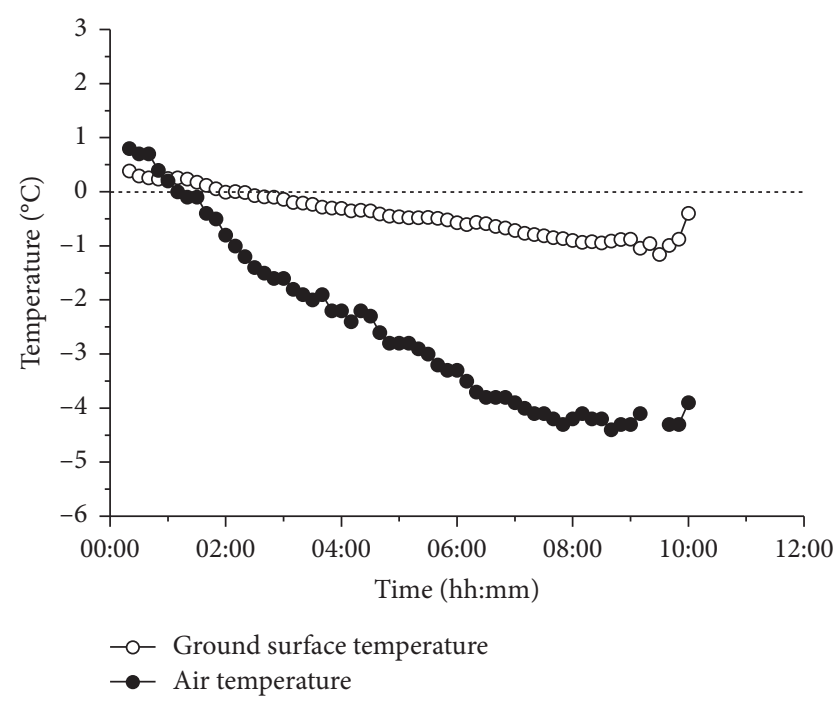

(a)

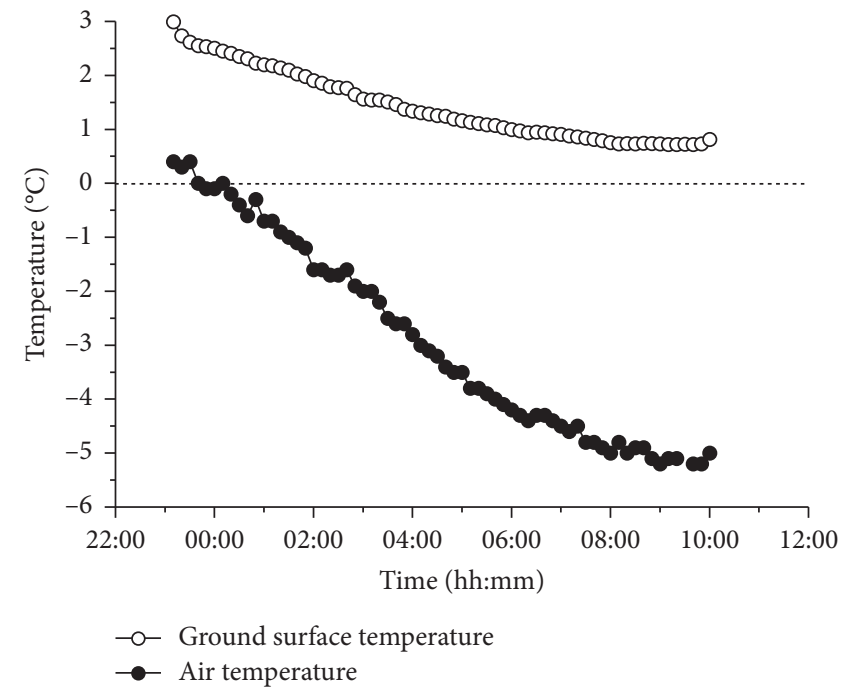

(b)

FiguRE 12: Variation of air temperature and ground surface temperature of the loose gravelly soil with covering the thermal insulation materials with time. (a) December 9, 2018. (b) December 14, 2018.

monitoring data of the monitoring system, it is possible to timely analyze and evaluate the region and range of the freeze-thaw process of soils, as well as the possible effects and impacts. Therefore, the on-site freeze-thaw monitoring system should be one of the important parts of the prevention and control system of winter construction. The monitoring system should be established in terms of the monitoring principles, methods, and contents, as well as the identification and evaluation systems.

(1) In terms of the monitoring principles: the monitoring system should carry out different levels and aspects of monitoring for different sites such as the dam core wall, Canpeichang, and Beiliaocang according to the actual situation on-site. Taking the dam core wall as an example, it should be established in all dimensions from different dimensions such as time and space. In terms of time, the entire winter (from mid-November to early March of the following year in Lianghekou) construction process should be monitored. During the construction process on the current day, continuous monitoring should be possible, and in particular, the continuous changing process of the monitoring content at night should be ensured. In terms of spatial distribution, it should be able to range from the ground surface temperature of the construction surface of the dam core wall to the ground surface temperature of the typical temperature characteristic unit. For example, in different regions of the Lianghekou construction site with different sunshine, the filling and compacting processes are different. And the ground temperature conditions at different depths of the typical temperature characteristic units. As a result, a three-dimensional monitoring system with different levels, interrelated and temperature as the core, is established.
(2) In terms of methods and contents: through the comprehensive application of the technical methods such as the long-distance and near-distance infrared detection, temperature probe monitoring, instruments and artificial recognition of freeze-thaw, meteorological monitoring, the meteorological conditions (wind speed, air temperature, solar radiation, precipitation, etc.), ground surface temperature, ground temperature at different depths of soil, and the freeze-thaw condition of the ground surface can be observed, monitored, and identified. As a result, a multielements comprehensive observational method has been formed, which include the meteorological conditions and ground temperature, automatic and manual, qualitative, and quantitative observations.

(3) Evaluation and prediction: through the establishment of the whole dam surface and three-dimensional observational database, as well as combined with the analysis of the characteristics and variations of the freeze-thaw, it is possible to carry out the evaluation of the freezing region, status, and the engineering impact during the construction process. At the same time, it can also carry out the predictive analysis based on this, and provide references and suggestions for the field construction decisions.

\section{Conclusions}

In view of the winter construction process of the dam core wall of the Lianghekou Hydropower Station under construction in the seasonally frozen soil area, according to the on-site meteorological conditions and the ground temperature observational data in the winter of 2016-2018, the freeze-thaw process of the main filling soils (gravelly soil and 
contact clay) and the effect of freeze-thaw on the engineering properties of soils were studied. Then, a comprehensive freeze prevention and control system for the soils was established. The following main conclusions were drawn:

(1) During the winter construction period of the Lianghekou Hydropower Station, which is located in the seasonally frozen soil area, the construction site of the dam core wall has the environmental conditions for the development of the short-term frozen soil. The soil will undergo a freeze-thaw process that freezes on most of the nights and thaws for the major part of the day. There will be a large number of thin or integral cryostructures formed inside the soil after freeze-thaw, which will affect the physical and mechanical properties, permeability, and other engineering properties of soil, and directly affect the filling quality of soil on-site.

(2) Based on the analysis of the measured data, it is found that the freezing characteristics and frequency of soils will change under different environments and construction conditions. Adjusting the construction schedule and coverage frequency, changing the initial temperature of the incoming soil, maintaining and slowing down the cooling process of soil after filling, changing the heat exchange process of soil by covering the loose soil and the thermal insulation materials on the surface of the compacted soil, and effectively controlling the development and existence of cryostructure will have important effects on the on-site freeze prevention and control of engineering quality.

(3) Through the research on the freeze-thaw process of the filling soil, the freeze-thaw effect of the loose soil, and the energy balance process of soils, the freeze prevention and control principles, as well as methods suitable for the winter construction process of the dam core wall have been established. Through the comparative analysis of the changing process of air and ground temperature, in different periods, different methods of covering loose soil and timely covering the thermal insulation materials are proposed for different types of soils, which play an important role in ensuring the filling quality of soils, shortening the construction duration, and reducing the engineering cost.

(4) This article mainly carried out relevant analysis and research on the winter construction process in Lianghekou Hydropower Station. The project is located in the typical seasonally frozen soil area in China, the construction will continue throughout the whole winter, and the construction of the dam core wall with tens of thousands of square meters area, high-quality construction requirements. Therefore, making the research results of this article have good typicality and representativeness and have a good reference for the similar projects in this type of regions.

\section{Data Availability}

The data used to support the findings of this study have not been made available because the experimental data involved in the paper are all obtained based on the authors' designed experiments and need to be kept confidential. The data are still being used for further research.

\section{Conflicts of Interest}

The authors declare that they have no conflicts of interest.

\section{Acknowledgments}

The work was supported by the Second Tibetan Plateau Scientific Expedition and Research (STEP) Program (Grant no. 2019QZKK0905), National Natural Science Funds of China (Grant no. 42071095), and the Science and Technology Project of Yalong River Hydropower Development Company (Grant no. YLLHK-LHA-2019006).

\section{References}

[1] T. Zhang, R. L. Armstrong, and J. Smith, "Investigation of the near-surface soil freeze-thaw cycle in the contiguous United States: algorithm development and validation," Journal of Geophysical Research, vol. 108, no. D22, pp. 1-14, 2003.

[2] K. Wang, T. Zhang, and X. Zhong, "Changes in the timing and duration of the near-surface soil freeze/thaw status from 1956 to 2006 across China," The Cryosphere, vol. 9, no. 3, pp. 1321-1331, 2015.

[3] L. Zhao, C. L. Ping, D. Yang, G. Cheng, Y. Ding, and S. Liu, "Changes of climate and seasonally frozen ground over the past 30 years in Qinghai-Xizang (Tibetan) Plateau, China," Global and Planetary Change, vol. 43, no. 1-2, pp. 19-31, 2004.

[4] G. Y. Liu, C. W. Xie, and S. H. Yang, "Spatial and temporal variation characteristics on the onset dates of freezing and thawing of active layer and its influence factors in permafrost regions along the Qinghai-Tibet Highway," Journal of Glaciology and Geocryology, vol. 40, no. 6, pp. 1067-1078, 2018, in Chinese.

[5] M. X. Yang, C. D. Yao, and X. H. Gou, "Freeze-thaw process of soil along the Qinghai-Tibet Highway and water-heat distribution characteristics," Progress in Nature Science, vol. 10, no. 5, pp. 443-450, 2000, in Chinese.

[6] Y. W. Zhou, D. X. Guo, G. D. Cheng et al., Frozen Soil in China, Science Press, Beijing, China, 2000, in Chinese.

[7] Z. W. Wu and Y. Z. Liu, Frozen Ground and Engineering Construction, Ocean Press, North Melbourne, Australia, 2005, in Chinese.

[8] X. Z. Xu, J. C. Wang, and L. X. Zhang, Frozen Soil Physics, Science Press, Beijing, China, 2010, in Chinese.

[9] N. K. Tovey, "Quantitative analysis of electron micrographs of soil microstructure," in Proceeding of the International Symposium on Soil Structure, pp. 50-58, Moscow, Russia, August 1973.

[10] M. Ghazavi and M. Roustaie, "The influence of freeze-thaw cycles on the unconfined compressive strength of fiberreinforced clay," Cold Regions Science and Technology, vol. 61, no. 2-3, pp. 125-131, 2010.

[11] M. Christ and Y. C. Kim, "Experimental study on the physicalmechanical properties of frozen silt," KSCE Journal of Civil Engineering, vol. 13, no. 5, pp. 317-324, 2009. 
[12] M. D. Shen, Z. W. Zhou, and S. J. Zhang, "Effect of stress path on mechanical behaviours of frozen subgrade soil," Road Materials and Pavement Design, .

[13] Z. W. Zhou, W. Ma, S. J. Zhang, Y. H. Mu, and G. Y. Li, "Experimental investigation of the path-dependent strength and deformation behaviours of frozen loess," Engineering Geology, vol. 265, Article ID 105449.

[14] L. Wang, F. X. Guo, Y. Q. Lin, H. Yang, and S. W. Tang, "Comparison between the effects of phosphorous slag and fly ash on the C-S-H structure, long-term hydration heat and volume deformation of cement-based materials," Construction and Building Materials, vol. 250, Article ID 118807, 2020.

[15] L. Wang, T. S. He, Y. X. Zhou et al., "The influence of fiber type and length on the cracking resistance, durability and pore structure of face slab concrete," Construction and Building Materials, vol. 2822021, Article ID 122706.

[16] Z. T. Wang, "Problems in winter construction of laxiwa hydropower station," Water Conservancy Science and Technology and Economy, vol. 20, no. 8, pp. 109-113, 2014, in Chinese.

[17] J. B. Wang, Z. P. Wang, and F. J. Zhang, "Study on winter filling construction technologies of sand and gravelly material in Aertashi dam," Water Power, vol. 44, no. 2, pp. 80-83, 2018, in Chinese.

[18] B. Wang, Q. F. Wang, and J. Zhou, "Construction of impervious soil in Xiaolangdi dam," Northwest Hydropower, vol. 4, pp. 36-39, 1999, in Chinese.

[19] P. L. Que, "Research on winter construction of crushed stone soil core wall of Shuiniujia Hydropower Station Dam," Water conservancy and Hydropower Construction, vol. 4, pp. 116119, 2013, in Chinese.

[20] L. N. Zhu, Z. W. Wu, Y. Z. Liu, X. M. Guo, and D. Q. Li, "Effects of permafrost degradation on environment in the east of Qinghai-Xizang (Tibet) Plateau," Marine Geology \& Quaternary Geology, vol. 15, no. 3, pp. 129-136, 1995, in Chinese.

[21] L. N. Zhu, Z. W. Wu, E. M. Zang, B. W. Pan, Y. Z. Liu, and G. X. Tao, "Difference of permafrost degeneration in the east of the Tibetan Plateau," Journal of Glaciology and Geocryology, vol. 18, no. 2, pp. 104-110, 1996, in Chinese.

[22] S. L. Wang, X. R. Luo, and P. F. Guo, "The distributive characteristics of frozen ground in the east of Qinghai-Xizang Plateau," Journal of Glaciology and Geocryology, vol. 13, no. 2, pp. 131-140, 1991, in Chinese.

[23] G. Q. Qiu, J. R. Liu, and H. X. Liu, Frozen Soil Physics, Gansu Science and Technology Press, Lanzhou, China, 1994, in Chinese.

[24] P. Viklander, "Permeability and volume changes in till due to cyclic freeze/thaw," Canadian Geotechnical Journal, vol. 35, no. 3, pp. 471-477, 1998.

[25] J. C. Edwin and J. G. Anthony, "Effect of freezing and thawing on the permeability and structure of soils," Engineering Geology, vol. 13, no. 1-4, pp. 73-92, 1979.

[26] K. D. Eigenbrod, "Effects of cyclic freezing and thawing on volume changes and permeabilities of soft fine-gained soils," Canadian Geotechnical Journal, vol. 33, no. 4, pp. 529-537, 1996.

[27] X. X. Chang, W. Ma, and D. Y. Wang, "Study on the strength of frozen clay at high confining pressure," Journal of Glaciology and Geocryology, vol. 29, no. 4, pp. 636-639, 2007, in Chinese.

[28] M. Huo, S. J. Wang, J. Z. Zhang, and L. Jin, "Experimental study on influences of water content and temperature on mechanical properties of ice-rich frozen soil," Journal of
Hydraulic Engineering, vol. 41, no. 10, pp. 1165-1172, 2010, in Chinese.

[29] X. Zhu, Z. Y. Cai, Y. H. Huang, C. Zhang, and W. L. Guo, "Research on mechanical properties of expansive soils under cyclic action of coupling wetting-drying and freeze-thaw and density," Journal of Hydraulic Engineering, vol. 51, no. 3, pp. 286-294, 2020, in Chinese.

[30] S. Tang, Y. Wang, Z. C. Geng, and X. F. Xu, "Structure, fractality, mechanics and durability of calcium silicate hydrates," Fractal and Fractional, vol. 5, no. 2, Article ID 5020047, 2021.

[31] H. Y. Wang, S. R. Tang, Y. H. Xing, and X. K. Zhang, "Hydraulic conductivity of compacted wide grading gravel soils under freeze-thaw cycling," Journal of Engineering Geology, vol. 23, no. 3, pp. 498-504, 2015, in Chinese.

[32] T. F. Zimmie and C. LaPlante, "The effect of freeze-thaw cycles on the permeability of a fine-grained soil," in Proceedings of 22nd Mid-Atlantic Industrial Waste Conference, pp. 580-593, Drexel University, Phailadelphia, PenSylvania, June 1990.

[33] J. Xu, Z. Q. Wang, J. W. Ren, and J. Yuan, "Experimental research on permeability of undisturbed loess during the freeze-thaw process," Journal of Hydraulic Engineering, vol. 47, no. 9, pp. 1208-1217, 2016, in Chinese.

[34] X. Huang, D. Q. Li, F. Ming, H. Bing, and W. W. Peng, "Experimental study of the compressive and tensile strengths of artificial frozen soil," Journal of Glaciology and Geocryology, vol. 38, no. 5, pp. 1346-1352, 2016, in Chinese.

[35] H. P. Li, C. N. Lin, J. B. Zhang, and Y. L. Zhu, "Uniaxial compressive strength of saturated frozen clay at constant strain rate," Chinese Journal of Geotechnical Engineering, vol. 26, no. 1, pp. 105-109, 2004, in Chinese.

[36] T. F. Hu, J. K. Liu, Q. Z. Wang, and J. H. Fang, "Experimental study on undrained strength characteristics of silty clay after freeze-thaw cycling," Journal of Central South University, vol. 49, no. 6, pp. 1481-1490, 2018, in Chinese.

[37] S. Yin, L. Li, and Y. D. Bian, "Experimental study on shear performance of compaction silt under frozen-thaw cycle," Highway Engineering, vol. 44, no. 5, pp. 42-46, 2019, in Chinese.

[38] Z. Zhang, W. Ma, and J. L. Qi, "Structure evolution and mechanism of engineering properties change of soils under effect of freeze-thaw cycle," Journal of Jilin University (Earth Science Edition), vol. 43, no. 6, pp. 1904-1914, 2013, in Chinese.

[39] H. Bing and W. Ma, "Experimental study on freezing point of saline soil," Journal of Glaciology and Geocryology, vol. 33, no. 5, pp. 1106-1113, 2011, in Chinese.

[40] H. Bing and W. Ma, "Laboratory investigation of the freezing point of saline soil," Cold Regions Science and Technology, vol. 67, no. 1-2, pp. 79-88, 2011.

[41] National Economic and Trade Commission of the People's Republic of China, DL/T 5129-2013 Construction Specification of Roller Compacted Earth-Rock Dam, China Electric Press, Beijing, China, 2013, in Chinese. 